\title{
Stress cardiomyopathy following thyroidectomy in a premenopausal woman with thyroid cancer: case report and review of the literature
}

\author{
Tiezhu Yao ${ }^{1}$, Lin Chen ${ }^{2}$, Jingtao $\mathrm{Ma}^{1}$, Zhenjie $\mathrm{Hu}^{3}$, Yuhong Chen ${ }^{3}$ \\ ${ }^{1}$ Department of Cardiology, The Fourth Hospital of Hebei Medical University, Shijiazhuang, China; ${ }^{2}$ Department of radiology, Shijiazhuang People's \\ Hospital, Shijiazhuang, China; ${ }^{3}$ Department of Critical Care Medicine, The Fourth Hospital of Hebei Medical University, Hebei Key Laboratory of \\ Critical Disease Mechanism and intervention, Shijiazhuang, China \\ Correspondence to: Yuhong Chen; Zhenjie Hu. Department of Critical Care Medicine, The Fourth Hospital of Hebei Medical University, Hebei Key \\ Laboratory of Critical Disease Mechanism and intervention, 12 Jiankang Road, Shijiazhuang 050017, China. \\ Email: yuhong_apple@126.com; syicu@vip.sina.com.
}

\begin{abstract}
Stress cardiomyopathy (SC) is a poorly recognized heart disease that was initially regarded as a benign condition. Recently, it has been shown that SC may be associated with severe clinical complications including death and that its prevalence is probably underestimated. The disease is characterized by transient systolic and diastolic left ventricular (LV) dysfunction with a variety of wall-motion abnormalities. It predominantly affects postmenopausal women and is often preceded by an emotional or physical trigger, but the condition has also been reported with no evident trigger. The striking preponderance of postmenopausal females suggests a hormonal influence. Potentially, declining oestrogen levels after menopause increase the susceptibility to SC in women. Oestrogens can influence vasomotor tone via up-regulation of endothelial NO synthase. Also, there is evidence that oestrogens can attenuate catecholamine-mediated vasoconstriction and decrease the sympathetic response to mental stress in perimenopausal women. Rare cases of SC following thyroidectomy in premenopausal women have been described. Currently, the pathogenesis of SC remains obscure, several possible hypotheses include catecholamine induced myocardial spasm or catecholamine related myocardial stunning, metabolic disorders and coronary microvascular damage. So prompt diagnosis and optimal management are crucial to obtaining a good outcome for the patient. We report an extremely rare case of SC induced by thyroidectomy in a premenopausal woman with cancer, and share our personal experience by reviewing the literature.
\end{abstract}

Keywords: Stress cardiomyopathy; Takotsubo cardiomyopathy; left ventricular dysfunction; perioperative period; thyroidectomy

Submitted Nov 06, 2020. Accepted for publication Dec 16, 2020.

doi: $10.21037 / g s-20-855$

View this article at: http://dx.doi.org/10.21037/gs-20-855

\section{Introduction}

Stress cardiomyopathy (SC), also known as 'Takotsubo syndrome', 'broken heart syndrome' or 'apical ballooning syndrome', mimics acute myocardial infarction (AMI). It is characterized by acute and reversible left ventricular (LV) dysfunction, is frequently caused by emotional or physical stress, and predominantly occurs in postmenopausal women, especially those older than 55 years (1). We present a case of SC following thyroidectomy in a premenopausal woman, which is rarely reported, and discuss the diagnosis and management by reviewing the published literature. We present the following article in accordance with the CARE reporting checklist (available at http://dx.doi.org/10.21037/ gs-20-855). 


\section{Case presentation}

A 37-year-old woman was hospitalized in the Department of Otolaryngology of The Fourth Hospital of Hebei Medical University with a mass in the thyroid. She had no past medical history or risk factors of coronary heart disease. Her preoperative examinations, including electrocardiography (EGG), chest X-ray, echocardiography, and blood tests, were normal. The patient underwent left thyroidectomy and lymph node dissection under general anesthesia, and the operation was completed successfully. After extubation, she was coughing, with pink, frothy sputum, and vomiting. She was slightly irritable, her pulse was 112 beats/min, blood pressure was $100 / 55 \mathrm{mmHg}$, and oxygen saturation decreased to $85 \%$ with high-flow oxygen mask. Chest auscultation revealed crackles throughout. After re-intubation, she was transferred to the Department of Critical Care Medicine for further diagnosis and therapy. Chest X-ray showed ground-glass opacities in both lungs (Figure 1A), and ECG showed new ST-segment depression in leads II, III, AVF, and V1-V5 (Figure 1B). Ultrasonic echocardiography (UCG) showed hypokinetic motion of the left mid-ventricular segment, followed by LV ejection fraction (LVEF) decrease to $36 \%$ (Figure $2 A$ ). Plasma cardiac enzymes were mildly elevated: troponin I was $3.44 \mathrm{ng} / \mathrm{mL}$ (normal range $<0.04 \mathrm{ng} / \mathrm{mL}$ ), myoglobin was $107.6 \mathrm{U} / \mathrm{L} \mathrm{ng} / \mathrm{mL}$ (normal range, $1.50-70.00 \mathrm{ng} / \mathrm{mL}$ ), and B-type natriuretic peptide (BNP) was $1,478.87 \mathrm{pg} / \mathrm{mL}$ (normal range $0.00-100.00 \mathrm{pg} / \mathrm{mL}$ ). Total thyroxine and total triiodothyronine were $89.93 \mathrm{nmol} / \mathrm{L}(78.38-157.40 \mathrm{nmol} / \mathrm{L})$ and $1.41 \mathrm{nmol} / \mathrm{L}(1.01-2.48 \mathrm{nmol} / \mathrm{L})$, respectively. Free thyroxine and free triiodothyronine were $10.61 \mathrm{pmol} / \mathrm{L}$ (7.86-14.41 pmol/L) and $4.37 \mathrm{pmol} / \mathrm{L}(3.80-6.00 \mathrm{pmol} / \mathrm{L})$, respectively. Thyroid-stimulating hormone and antithyroid peroxidase antibody were $2.49 \mathrm{mIU} / \mathrm{L}(0.34-5.60 \mathrm{mIU} / \mathrm{L})$ and $0.40 \mathrm{IU} / \mathrm{mL}(0.00-9.00 \mathrm{IU} / \mathrm{mL})$, respectively. A provisional diagnosis of SC was made, but the patient's husband refused coronary angiography for differential diagnosis with AMI.

The patient received analgesia, deep sedation, mechanical ventilation, anticoagulation, cardioprotective drugs, antibiotics, levosimendan, and other supportive therapy. She was also administered low-dose norepinephrine to maintain normal blood pressure. Cardiac function was measured by bedside ultrasonography, which also played an important role in fluid management by assessing inferior vena cava (IVC). Troponin I increased to $16.05 \mathrm{ng} / \mathrm{mL}$ at $24 \mathrm{~h}$ after onset, but there were no significant changes on ECG and UCG. Hence, computed tomographic angiography (CTA) was immediately performed, which showed normal coronary arteries without significant stenosis (Figure 2B).

Subsequently, the patient's condition gradually improved, and she was extubated after 6 days of ventilation before being transferred to the Department of Cardiology. At that point, echocardiography showed restoration of LVEF to $60 \%$. At 9 days after transfer, cardiac magnetic resonance (CMR) was performed, which showed normal ventricular function without fibrosis or irreversible necrosis (Figure 2C). She was discharged from hospital 3 weeks after surgery without symptoms.

Informed written consent was given by the patient's relatives for publication of the case report and accompanying images. All procedures performed in studies involving human participants were in accordance with the ethical standards of the institutional and/or national research committee(s) and with the Helsinki Declaration (as revised in 2013).

\section{Discussion}

SC was first described as Takotsubo cardiomyopathy in 1990 in Japan because the echocardiographic appearance of the $\mathrm{LV}$ in systole was similar to that of an octopus pot (2). Based on the previous literature, SC typically occurs in postmenopausal women after suffering emotional stress, and characteristically shows acute LV apical ballooning $(3,4)$. According to the International Takotsubo Registry, $79.1 \%$ of SC patients are women older than 50 years (5), so its occurrence may be associated with lower estrogen levels (1). SC can be promoted by multiple predisposing factors; physical stressors (e.g., surgery, postoperative stress, infection, cancer and respiratory failure) are more frequent than emotional stressors (e.g., anger, anxiety, grief and fear) (36\% vs. $27.7 \%$, respectively), and approximately $28.5 \%$ of patients report no precipitating triggers $(1,5)$. The pathogenesis of SC remains obscure; several possible hypotheses include catecholamine-induced myocardial spasm or direct catecholamine-associated myocardial stunning, metabolic disturbance, and coronary microvascular impairment (6). In this case report, we considered the leading cause of SC was the surgery, but other potential reasons include residual neuromuscular blockade, laryngospasm after extubation, vocal cord injury, and decreased thyroid hormone levels. Acute pulmonary edema was an early complication but not a cause of SC. 

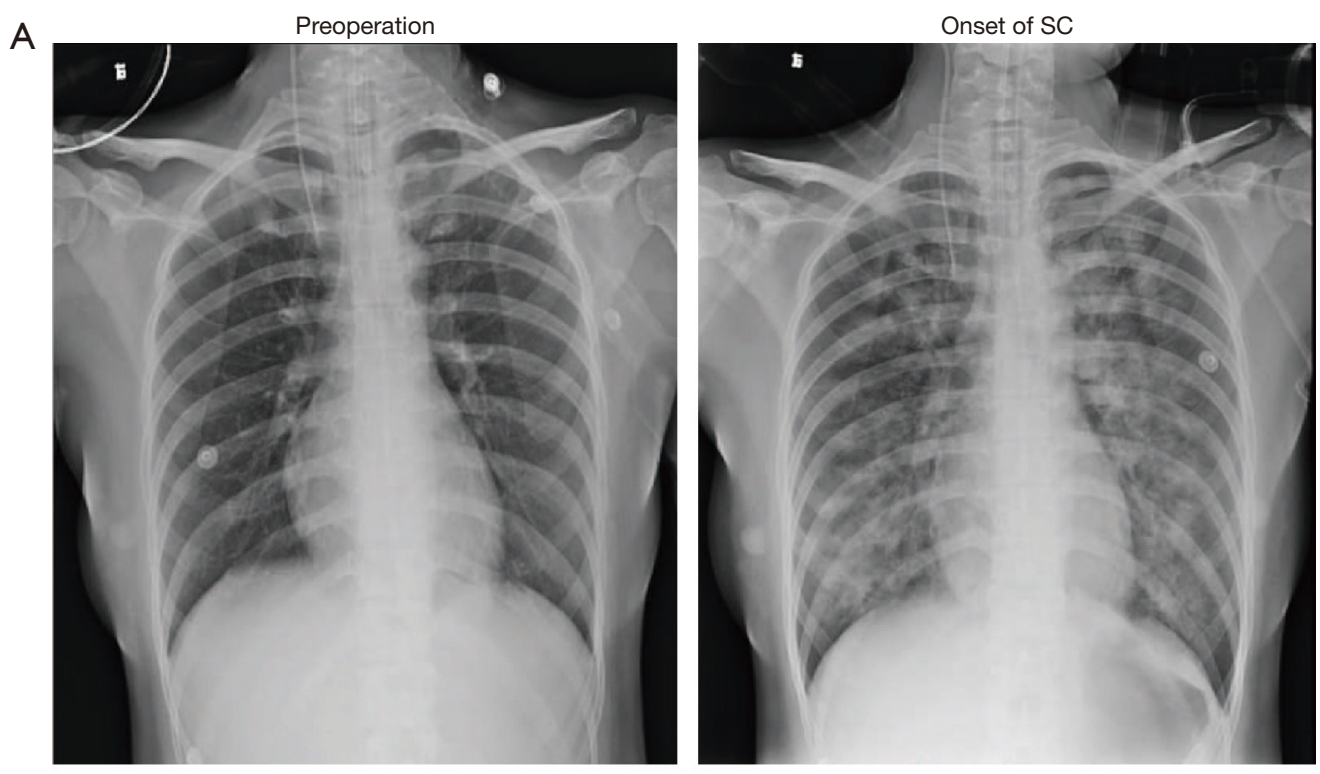

B
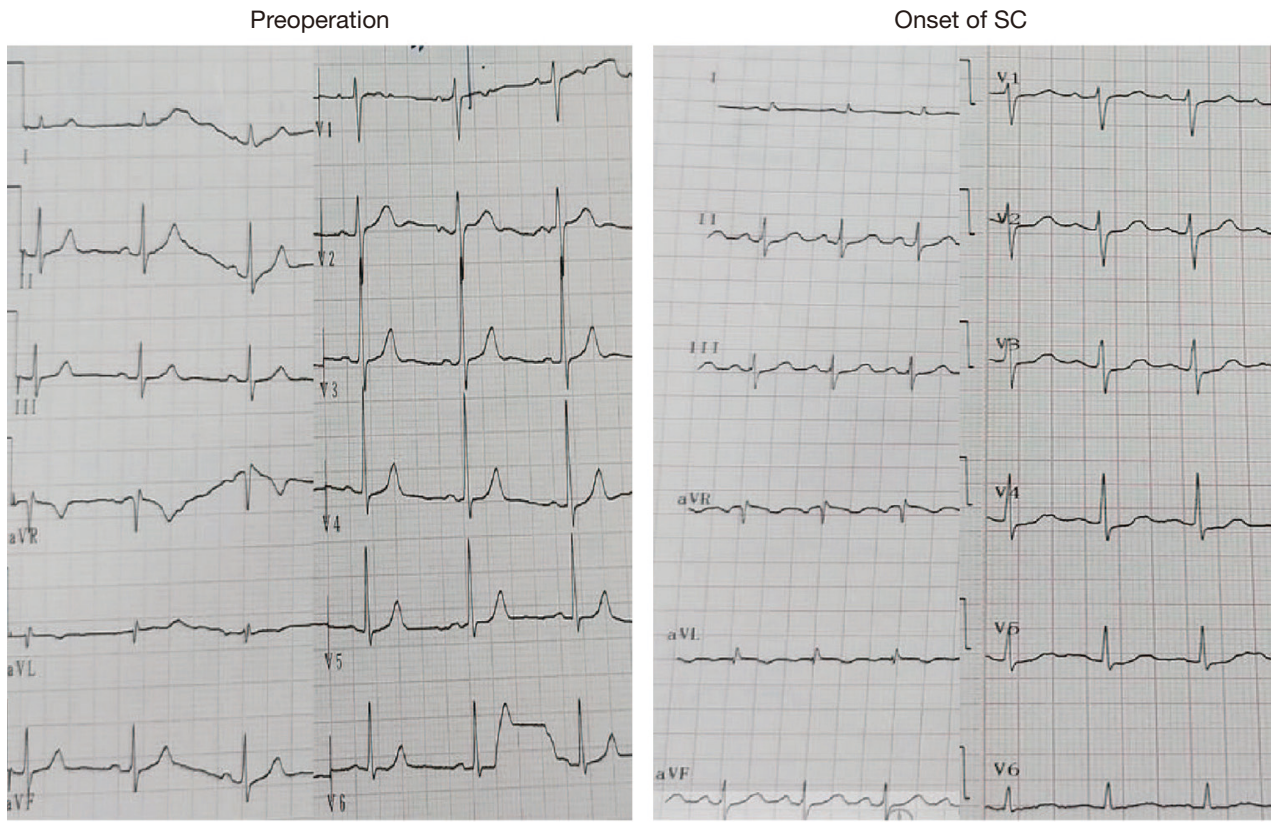

Figure 1 Changes in Chest X-ray chest and electrocardiogram. (A) Chest X-ray showing ground-glass opacities in both lungs on the onset of SC. (B) Electrocardiogram showing new ST-segment in leads of II, III, AVF and V1-V5.

The presentation of SC mimics that of AMI, and 50$60 \%$ patients present with chest pain of recent onset (7). ECG changes include ST-segment elevation or depression, abnormal Q-waves, and nonspecific T-wave changes, but ECG can be normal at presentation (8). The levels of serum cardiac biomarkers are mildly raised and that of BNP may be markedly elevated (1). The first-choice noninvasive imaging technique for diagnosis of SC is UCG. There are three patterns of $\mathrm{LV}$ uncoordinated wall motion, and approximately $70-80 \%$ of SC cases present with apical ballooning, while the mid-ventricular ballooning pattern and basal ballooning pattern occur in $10-20 \%$ and $1-2 \%$ of patients, respectively $(3,9)$. Coronary angiography remains the gold standard in differentiating SC from coronary heart disease. CTA and CMR can be performed if SC patients have contraindications to coronary angiography $(10,11)$. 


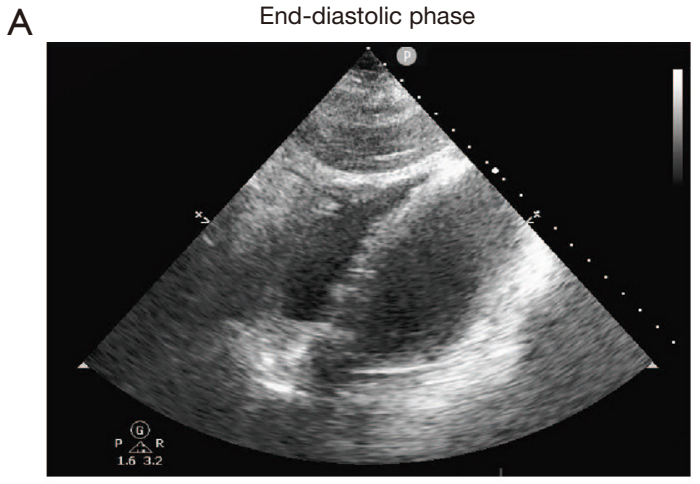

B

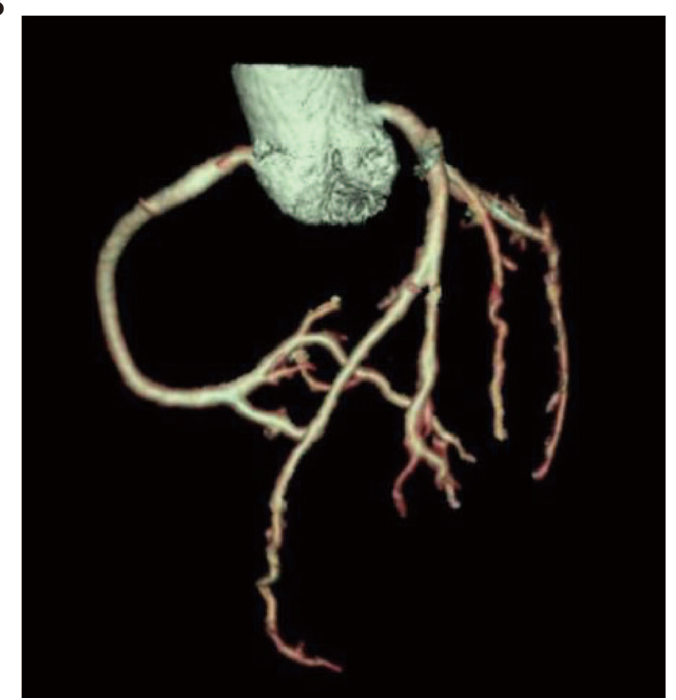

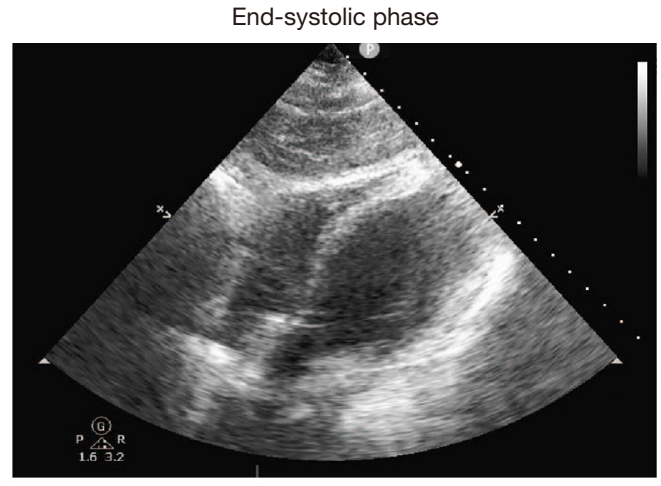

End-diastolic phase

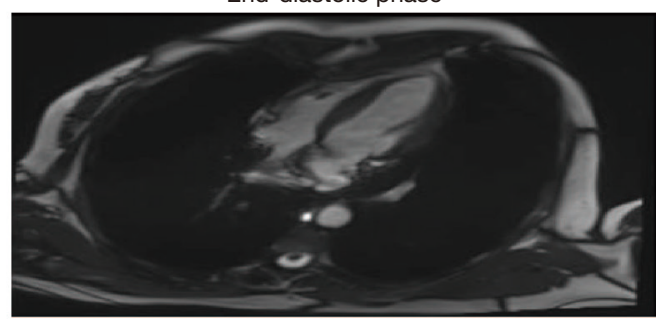

End-systolic phase

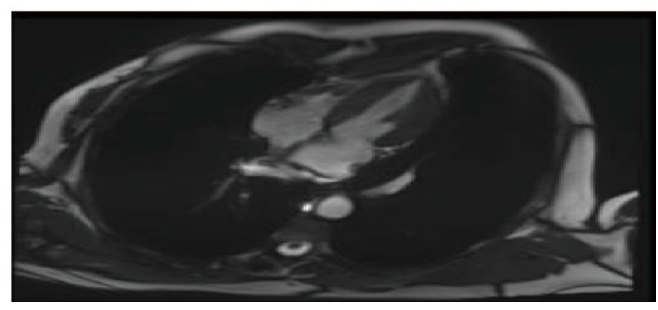

Figure 2 Image data of myocardium and coronary artery. (A) Ultrasonic echocardiography showing mid-ventricular ballooning in left ventricle. (B) Computed tomographic angiography showing normal coronary arteries without significant stenosis. (C) Cardiac magnetic resonance showing normal ventricular function without fibrosis and irreversible necrosis.

The diagnostic criteria for SC are controversial, and the most frequently utilized are the modified Mayo clinic criteria (12). The present patient's UCG findings were consistent with a diagnosis of SC. Curiously, her serum troponin I level was highest in the first $24 \mathrm{~h}$, peaking at $16.05 \mathrm{ng} / \mathrm{mL}$, which was incompatible with changes on ECG and UCG. The patient's husband refused permission for invasive coronary angiography, so we selected CTA and CMR to make a definitive diagnosis.

Treatment of SC is similar to that for AMI and primarily supportive. The integrated management strategy includes sedation or analgesics, $\beta$-blockers, angiotensin- converting enzyme inhibitors/angiotensin receptor blockers, diuretics, and cardiac mechanical support if needed (1). It is better to avoid $\beta$-blockade if the patient has hemodynamic instability, because it may worsen hypotension. The use of catecholamine-sparing positive inotropic agents, especially dobutamine, may cause obstruction of the LV outflow tract or worsen catecholamine-induced myocardial stunning and also should be avoided $(13,14)$. Continuous hemodynamic monitoring and bedside ultrasonography should be used to assess the cardiovascular status in SC patients with hypotension (11). Levosimendan, a new type of $\mathrm{Ca}^{2+}$ sensitizer, could improve cardiac function as an alternative inotrope of catecholamine agents, and has been shown to be reliable, effective and safe in Chinese patients with SC (15). In this case, levosimendan was infused at $0.35 \mathrm{mg} / \mathrm{h}$, and the norepinephrine requirement gradually declined. Followup UCG revealed LV systolic function improvement with LVEF restored to $60 \%$. 
Patients with SC usually have an excellent prognosis, but in $5-22 \%$ of cases there may be a relapse (11). The recovery process may vary from a few hours to a few weeks, but usually takes 7-10 days (1). Although LVEF and cardiac biomarkers returned to normal, the patients should be followed for 3 months because impairment may be present.

\section{Conclusions}

A young premenopausal woman was diagnosed as a rare case of SC induced by thyroidectomy. Attention must be given to the management of the perioperative period and to the diagnosis and treatment of SC.

\section{Acknowledgments}

Funding: We thanked the patient for her cooperation during the treatment process. This study was supported by the Public Health Foundation of Hebei Province of China (20160156).

\section{Footnote}

Reporting Checklist: The authors have completed the CARE reporting checklist. Available at http://dx.doi.org/10.21037/ gs-20-855

Conflicts of Interest: All authors have completed the ICMJE uniform disclosure form (available at http://dx.doi. org/10.21037/gs-20-855). The authors have no conflicts of interest to declare.

Ethical Statement: All the data and the pictures are original. The authors are accountable for all aspects of the work in ensuring that questions related to the accuracy or integrity of any part of the work are appropriately investigated and resolved. Informed written consent was given by the patient's relatives for publication of the case report and accompanying images. All procedures performed in studies involving human participants were in accordance with the ethical standards of the institutional and/or national research committee(s) and with the Helsinki Declaration (as revised in 2013).

Open Access Statement: This is an Open Access article distributed in accordance with the Creative Commons Attribution-NonCommercial-NoDerivs 4.0 International License (CC BY-NC-ND 4.0), which permits the non- commercial replication and distribution of the article with the strict proviso that no changes or edits are made and the original work is properly cited (including links to both the formal publication through the relevant DOI and the license). See: https://creativecommons.org/licenses/by-nc-nd/4.0/.

\section{References}

1. Zhang L, Piña IL. Stress-Induced Cardiomyopathy. Heart Fail Clin 2019;15:41-53.

2. Dote K, Sato H, Tateishi H, et al. Myocardial stunning due to simultaneous multivessel coronary spasms: a review of 5 cases. J Cardiol 1991;21:203-14.

3. Sharkey SW. A Clinical Perspective of the Takotsubo Syndrome. Heart Fail Clin 2016;12:507-20.

4. Bertoni AG, Bonds DE, Thom T, et al. Acute coronary syndrome national statistics: challenges in definitions. Am Heart J 2005;149:1055-61.

5. Shin MJ, Rhee H, Kim IY, et al. Clinical features of patients with stress-induced cardiomyopathy associated with renal dysfunction: 7 case series in single center. BMC Nephrol 2013;14:213.

6. Ono R, Falcão LM. Takotsubo cardiomyopathy systematic review: Pathophysiologic process, clinical presentation and diagnostic approach to Takotsubo cardiomyopathy. Int J Cardiol 2016;209:196-205.

7. Gianni M, Dentali F, Grandi AM, et al. Apical ballooning syndrome or takotsubo cardiomyopathy: a systematic review. Eur Heart J 2006;27:1523-9.

8. Scally C, Choo W, Rudd A, et al. The early dynamic of ECG in Takotsubo syndrome presenting with STelevation: A comparison with age and gender-matched ST-elevation myocardial infarction. Int J Cardiol 2020;320:7-11.

9. Citro R, Pontone G, Pace L, et al. Contemporary Imaging in Takotsubo Syndrome. Heart Fail Clin 2016;12:559-75.

10. Nance JW, Schoepf UJ, Ramos-Duran L. Tako-tsubo cardiomyopathy: findings on cardiac CT and coronary catheterisation. Heart 2010;96:406-7.

11. Lyon AR, Bossone E, Schneider B, et al. Current state of knowledge on Takotsubo syndrome: a Position Statement from the Taskforce on Takotsubo Syndrome of the Heart Failure Association of the European Society of Cardiology. Eur J Heart Fail 2016;18:8-27.

12. Parodi G, Citro R, Bellandi B, et al. Revised clinical diagnostic criteria for Tako-tsubo syndrome: the Tako-tsubo Italian Network proposal. Int J Cardiol 2014;172:282-3. 
13. Boland TA, Lee VH, Bleck TP. Stress-induced cardiomyopathy. Crit Care Med 2015;43:686-93.

14. Webster KT, Apridonidze T, Mopala PR, et al. StressInduced Cardiomyopathy Complicated by Dynamic Left Ventricular Outflow Obstruction, Cardiogenic Shock, and

Cite this article as: Yao T, Chen L, Ma J, Hu Z, Chen Y. Stress cardiomyopathy following thyroidectomy in a premenopausal woman with thyroid cancer: case report and review of the literature. Gland Surg 2020;9(6):2187-2192. doi: 10.21037/gs20-855
Ventricular Septal Rupture. Can J Cardiol 2019;35:229.e7229.e9.

15. Guo Y, Zhou C, Yang X. Efficacy and safety of levosimendan in Chinese elderly patients with Takotsubo syndrome. Ann Transl Med 2018;6:438. 